\title{
Burundi and Wildlife: Problems of an Overcrowded Country
}

\author{
Jacques Verschuren
}

Despite its dense population Burundi still has a wildife remnant that includes hippopotamus, buffalo, waterbuck and bushbuck, crocodiles, monkeys and many birds, especially water birds. But there are no nature reserves, and there is no legal protection. Now the Government has commissioned wildlife surveys, including one by the author, and there are plans to create a 50,000-hectare national park in the Ruvubu Valley, as well as some smaller reserves, and to preserve the surviving forest on the Zaire-Nile watershed.

Is it possible for the most densely populated country in Africa, with no wildlife legislation, still to possess a valuable stock of wildlife? The answer, fortunately, is yes. With four million inhabitants in only 27,000 square kilometres, there are large areas of Burundi where population density is 400 inhabitants to the square kilometre - a figure comparable to the most urban and industrial regions of Europe or America. Ninety per cent of the land is densely occupied by man and heavily grazed by his abundant livestock. That some wildlife has survived at all is due to the fact that many of the inhabitants are mainly cattle-grazers, and, as is the case with rural peoples all over Africa, this way of life generally engenders respect for wildlife. Gradually the Burundi Government has come to realise the importance of conservation and decided to act, and several research missions, including my own in 1976, have now put forward concrete proposals for conservation. The priorities are a responsible administrative body with a corps of wardens in the field, a series of nature reserves, and legislation to protect species.

Situated at the geographical heart of Africa, a little south of the Equator, Burundi forms part of the drainage of the high tributaries of the Nile and the

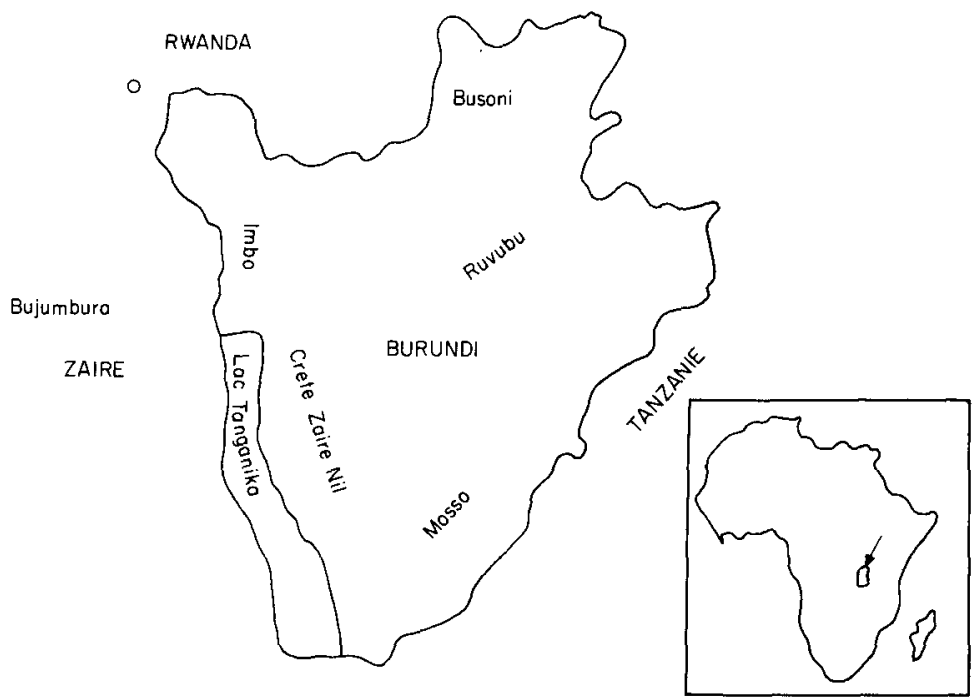


Zaire; here is the 'authentic' source of the Nile. But seen from the air, most of Burundi resembles a huge kitchen garden with myriads of scattered dwellings. The hills are all either cultivated or planted with eucalyptus to combat the struggle against erosion and provide firewood, a need that is given absolute priority in this country. Genets, civet cats, mongooses - the established predators of the numerous rodents - are extremely plentiful, but little else.

Of infinitely greater interest to the naturalist is the Zaire-Nile watershed, the backbone ridge of the country, which rises in places to over 2600 metres. Formerly forest covered its whole length, but today this is attacked on all sides by cultivation and woodcutting. In the south the forest has disappeared completely except for a few hundred hectares near Bururi, which contains the best Entandophragma in Africa. There are also vast stretches of bamboo Arundinaria, considered by some botanists to be secondary formations. Originally this high forest, whose total area today cannot exceed 35,000 ha ( 1.3 per cent of the country) harboured considerable numbers of animals, including mountain gorillas Gorilla $g$. beringei until a few decades ago (rumours of their presence today probably refer to chimpanzees), colobus monkeys Colobus polykomos and C. badius, and duikers Cephalophus; elephants occasionally come over from the larger forests of Rwanda. Large numbers of livestock use the forests but do not harm the trees. To preserve this forest is today the top priority for Burundi, not only to save the wildlife but for climatic reasons. The authorities are aware of this and have recently ordered that 'not a single tree may be cut down'. The 'bushmen' of the plains and the inhabitants of the capital also understand this, but it still remains to convince the inhabitants of the highlands, on whom everything depends. A very simple and persuasive argument is: 'If you use a thousand litres of water per year, do you prefer 999 litres on January 1 st and a single litre for the rest of the year, or three litres every day of the year? So - protect your forest sponge ...'

Two other regions interesting for their wildlife are the Imbo plain (the plain of the Rusizi river) in the west, between Lakes Kivu and Tanganyika, and the

\section{Waterbuck}




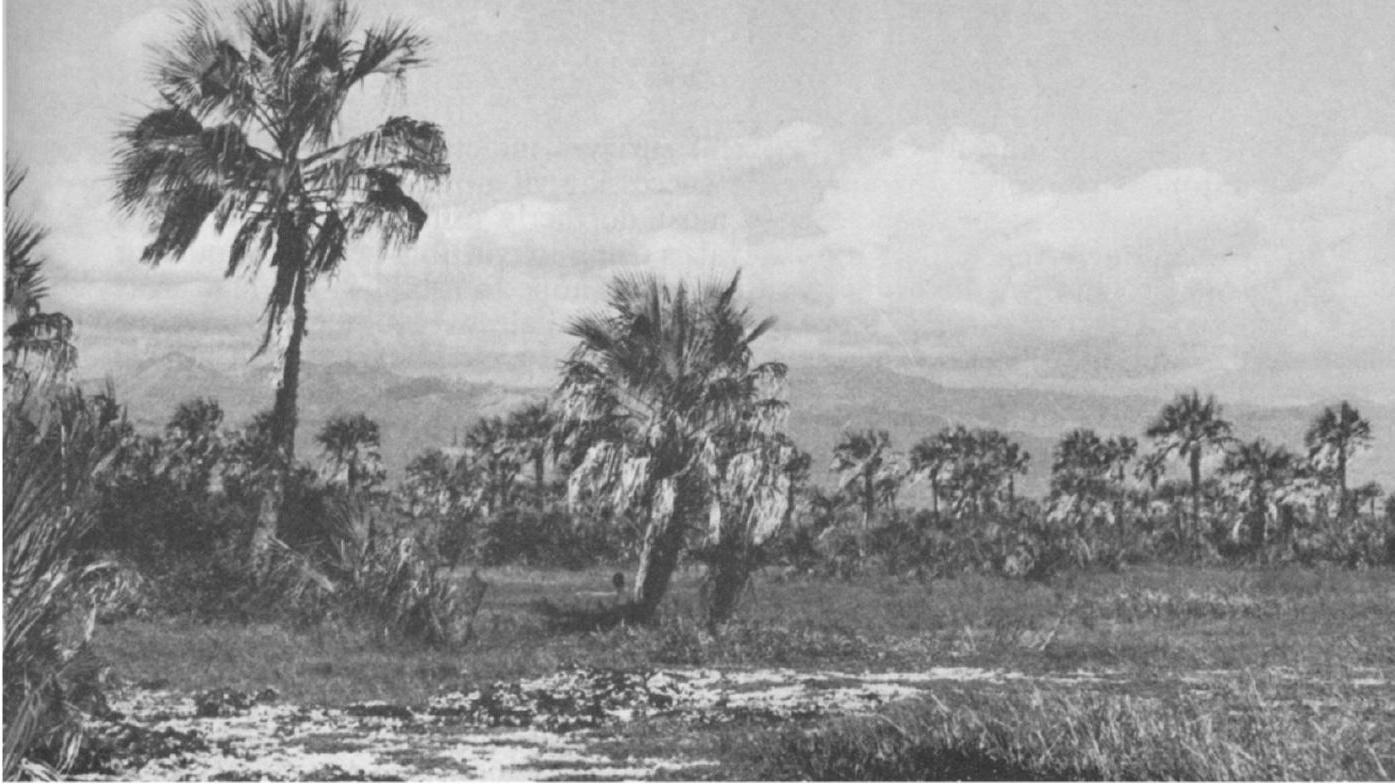

Hyphaene palms

depressions in the east, on the frontier with Rwanda and Tanzania.

The history of the Imbo plain is a typical one. A few decades ago it was a naturalists' paradise, with hippopotamus and hundreds of elephants and antelopes. But it was 'condemned' to cultivation and cattle, and today is only a shadow of what it was. Now, in extremis, they want to save something of it - there is even talk of re-introducing some species, for at present large game is limited to a few bushbuck, perhaps some sitatunga, 150 hippopotamus and crocodiles. Fortunately some hundreds of hectares of beautiful dry forest have been saved and these are to be protected. This is an area of great scientific interest with an endemic variety of palm Hyphaene benguellensis ventricosa. Fire-resistant, this forest presents an impressive spectacle against the background of the Itombwe range in Zaire, 3000 metres high and still the home of numerous gorillas.

Fortunately Imbo has maintained a remarkable ornithological interest, thanks to the 'passive protection' of the inhabitants, and as a result of having retained the swampy stretches and lagoons of the Rusizi delta. All the large African limicoline birds are to be seen in large numbers, especially yellowbilled stork Mycteria ibis, saddle-bill stork Ephippiorhynchus senegalensis and lesser flamingo Phoeniconaias minor. It is an important area for northern winter migrants, some of which pass through, and a breeding place for several species, including the African skimmer Rynchops flavirostris.

Several natural 'zoological curiosities' are protected in Bujumbura, Burundi's beautiful capital in the Imbo plain, including about thirty 'citizen' hippopotamus, sometimes to be seen on the tourist beaches or in the port, a large heronry, and some spectacular colonies of straw-coloured fruit bats Eidolon helvum. There are still 300 to 400 hippopotamus in the Rusizi and also, despite intense cultivation, on the banks of Lake Tanganyika, where crocodiles too have never been exterminated.

In the eastern part of the country the most interesting region-is the Ruvubu valley, a sort of Upper Nile, which drains a large part of the country. A stretch 
$125 \mathrm{~km}$ long and $3-5 \mathrm{~km}$ wide still survives intact, a snake-like strip of untouched nature consisting of a succession of meanders, meadows and riverine forests; it is one of the most northerly examples of Zambesian Brachystegia vegetation. Its survival is a miracle in this heavily populated country, and it is here that the authorities hope to establish the first great Burundi Park of about 50,000 ha. In Kirundi dialect Ruvubu means river of the hippopotamuses. There are over a thousand of them, as well as 500 buffaloes, several hundred antelopes, and above all bushbuck and waterbuck. The people still practise a traditional form of hunting which does not, however, have too great an impact. Water birds abound; recently we saw a marvellous assembly of more than a thousand white pelicans Pelecanus onocrotalus. Ruvubu will never become a second Serengeti, but it shows what can be achieved in such an over-populated country.

In the north of the country, the Busoni area, a continuation of the Rwandan Bugesera, was also a paradise for wildlife at one time. But the human population pressure is such that Burundi had to make a harrowing choice in deciding which natural sites to keep, and Busoni was not chosen. One great problem is the huge dam that is to be built on the Akagera river, which could have a tremendous ecological impact on the neighbouring countries, Rwanda and Tanzania, as well as on Burundi.

For a long time it was thought that the Mosso in the Malagarazi valley, in the south-east of the country, was an important reserve with abundant wildlife and few humans. But intensive poaching and cultivation projects have destroyed its value as a nature reserve. Perhaps hunting areas can be set up both here and in Busoni.

Two other possible reserves are being discussed. Not far from the frontier, in Tanzania, is the famous Gombe Stream Reserve, the chimpanzee reserve, and the possibility of a comparable one in Burundi has not been excluded; the second possibility is a site for a bird reserve to replace the famous Lake $\mathrm{R}$ wihinda, the Lake of Birds, where great numbers of storks and ibises used to nest, but which has been destroyed as a result of water-level chrnges (possibly man-made) that destroyed the nesting islands.

Nature is not completely condemned in Burundi. If these projects can be carried out soon they will show that some nature conservation can be achieved even in so crowded a country.

\section{Acknowledgment}

I wish to thank the Burundi authorities who gave me permission to conduct this preliminary inquiry, and Belgium-Burundi cooperation.

Dr J. Verschuren, Institut Royal des Sciences Naturelles de Belgique, Rue Vautier 31, B-1040 Brussels, Belgium.

\section{Sri Lanka Forest Saved}

Good news from Sri Lanka is that logging in the Sinharaja Forest has been completely stopped. As a result 12,000 acres of virgin rain forest have been saved. The battle for this forest has been a long one-when Oryx reported on it in 1973 (May, page 14) there were still 20,000 acres untouched. The Ceylon Wildlife and Nature Protection Society, in its representations to the Prime Minister, pointed out that the Sinharaja Forest had never been studied systematically and described it as 'the richest natural ecosystem with a large number of indigenous species'. 